\title{
An Investigation into the Effects of Computer Integrated Manufacturing Systems in the Productivity of SMEs in Pakistan
}

\author{
Ghulamyasin Shaikh, Department of Industrial Engineering and Management, \\ Mehran University of Engineering and Technology, Jamshoro, Sindh, Pakistan \\ Yasinshaikh2001@yahoo.com
}

Hussain Bux Marri, Department of Industrial Engineering and Management, Mehran University of Engineering and Technology, Jamshoro, Sindh, Pakistan hussainmarri@hotmail.com

Zahir Irani, Information systems Evaluation and Integration Network Group (ISEing) School of Information Systems, Computing and Mathematics, Brunel University West London , UK

Zahir.Irani@brunel.ac.uk

\begin{abstract}
The current dynamic and turbulent manufacturing environment has forced companies that compete globally to change their traditional methods of conducting business [Producer to consumer]. Recent developments in manufacturing and business operations have lead to the adoption of Computer Integrated Manufacturing (CIM) technologies that are based on systems and processes that support global competitiveness, especially for Small and Medium Enterprises (SMEs). Organizations and SMEs in particular need to re-evaluate every aspect of their manufacturing strategy and quickly move towards a CIM based environment where manufacturing technologies, business strategies and processes are integrated together. This paper highlights the development of a CIM adoption model that has resulted from empirical work generated from SMEs in Pakistan. The model consists of the parameters such as Top Management Support, System Integration, Marketing, and over all performance.
\end{abstract}

Keywords: Implementation, CI M, SMEs, Business, Empirical Analysis.

\section{INTRODUCTION}

In the world of business, Pakistan is emerging as a developing country to share its value and potential in to the mainstream, although yet to be done a lot so that it could come under the umbrella of developing countries. Agriculture, industry and trade play a significant role in the economic development of a country but the role of advanced manufacturing technologies in the overall development of the country is indispensable.

The origin of industrial development starts from traditional kind of manual manufacturer and keeps on crawling for further development, when the demand of the products raises the industrialist installs machines to cope the rise of demand and ultimately earns more profit. The continuing efforts of fixing, expanding and updating the industry to include modern technologies as per demand of market and time, the expanded industry becomes a complete industry and stands in the rank of world's leading industries of similar nature. To get better results, the companies should move towards Computer Integrated Manufacturing (CIM) system which is a combination of various techniques that are making essential changes to manufacturing companies (Lefebvre et al 1996).

In order to improve the efficiency, various advanced manufacturing systems have been being introduced to deal with increased demand of Small and Medium Enterprises (SMEs). CIM model is

Shaikh et al.,

An Investigation into the Effects of Computer Integrated Manufacturing Systems in the Productivity of SMEs in Pakistan 
developed to tackle the problems of SMEs and will help in minimizing the waste and ultimately enhancing profit in the broad sense.

This paper attempts to study the implementation of CIM in SMEs. The formation of the paper follows as: Section 2 of the paper presents the background of Small and Medium enterprises. Computer Integrated Manufacturing is presented in section 3. Research methodology and framework with the conceptual model for the implementation of CIM in SMEs is presented in section 4. An empirical study conducted with SMEs located in the province of Sindh in Pakistan has been offered in Section 5. Finally, the summary of findings and recommendations are presented in Section 6.

\section{SMALL AND MEDIUM ENTERPRISES (SMEs)}

In Pakistan, the concept of a SMEs is defined as a business with an investment of productive assets (not including land and building) ranging between(Rupees) Rs. 2-40 million and employing between 10-99 workers. It plays a significant role in the national economy and in providing employment opportunities. There are 3.2 million business enterprises employing up to 99\% persons, constitute over $95 \%$ of all private in the industrial sector and $78 \%$ of the non-agriculture labor force. They contribute over 30\% to the GDP, Rs.40 billion to export (SMEDA PAKISTAN web page.). However SMEs have not received adequate attention from Pakistani researchers and practitioners in improving their productivity, the Pakistani government should help these companies to improve their competitiveness to strengthen the national economy. It should also establish the technical training centers for human resource training, scientific and technological information centers for the competitiveness of all SMEs (Gunasekaran et al., 2002).

During the last one decade several factors (Quality, delivery, durability ) have forced manufacturers to make, required changes in their products, markets \& manufacturing strategies, there are some of the ways by which SMEs can achieve a competitive advantage in manufacturing is through the implementation of CIM (Gunasekaran et al., 2000). At the global market there is a strong pressure to the SMEs to coordinate their efforts to the latest Computer Aided Design (CAD) systems, numerically controlled (NC) machine tools, and their systems (Al Ahmari 2002).

The business environment where the technology is key to success and the use of technological resources has become a major strategic challenge for SMEs. The globalization of markets, growing interpenetration of economy and increased interdependence between partners are changing the foundations of competitiveness and economic performance of SMEs (Johansen et al., 2001). Much of the recent literature on CIM and flexible manufacturing system (FMS) suggests that SMEs implement the advanced system by which companies can maximize the productivity, reduction in lead time and better machine utilization (Groover et al., 1999).

Advanced Manufacturing Technologies (AMT) provides benefits and advantages in areas that would enable SMEs to maintain quality, operational, organizational and financial performances. AMT are a source of strategic competitive benefits, such as improved quality, greater flexibility and cost reduction (Dangayach and Deshmukh, 2005).

\section{COMPUTER INTEGRATED MANUFACTURING}

The term computer integrated manufacturing (CIM) is defined first by Harrington in 1978 and the first framework explaining the major components of CIM and their relationships was developed in 1981 by Arthur D. Little, Inc., followed by General Electric's “factory of the future” (Gunn 1987). The CIM system is the product of many scientific efforts for the application of automation systems to manufacture the variety of components this term is widely applied in the area of computer and communication technologies employed in manufacturing management (Browne et al., 1988). CIM has been the area of attention in many papers, textbooks, technical conferences, and seminars in the last

Shaikh et al.,

An Investigation into the Effects of Computer Integrated Manufacturing Systems in the Productivity of SMEs in Pakistan 
more than one decade, the aim of CIM is to achieve completely automated production, also referred to as "the factory of the future", by integrating the isolated automated production islands which have been the key solution to the problems existing in the discrete manufacturing industry. One could say that CIM had grown up and matured enough by 1988 to become a business strategy as well as the technology of the forth coming decade and beyond.

The significance of Computer integrated manufacturing (CIM) can not be ruled out in any manufacturing unit and this research will highlight the scope of SMEs and their future along with implications of implementing CIM in SMEs. By implementing the CIM system in SMEs, this will help in solving internal \& external problems and making appropriate actions to secure competitive advantages. It should be Pakistan's highest priorities to adopt the new and advanced technologies to meet the needs of people. Keeping in view the CIM as a computer oriented system, which helps SMEs to maximize the production to fulfill the requirements of the customer. This technology will also assist to minimize the time factors and labor efforts for the achievement of the objectives. Now days it is an appropriate time to implement the advance manufacturing technologies to bring our country's economy at par to get the rid of industrial collapse.

\section{RESEARCH METHODOLOGY}

This section identifies the nature of research methodology within which the research process can be conducted. There is a long standing debate surrounding the two traditional modes of data, viz. quantitative and qualitative. According to Bryman (1988) "quantitative research is, then, a genre which uses a special language which appears to exhibit some similarity to the ways in which scientists talk about how they investigate the nature order - variable control, measurement, and experiment”. On the other hand qualitative approaches aim to reflect the meanings people apply to their actions; how people make sense of their world from the perspective of those people.

In this paper, a quantitative approach has been applied. This approach is subjective, as is the data collected and compared in detailed, and the outcome is only as good as the questions developed. The research methodology employed here is based on a literature survey, a conceptual model and an empirical analysis using the data collection from the structured questionnaire from SMEs located in the province of Sindh in Pakistan. The objective of the survey is to investigate the awareness of SMEs concerning the implementation of CIM and to determine the extent to which this has changed the flexibility of manufacturing after it has been introduced.

The design of the questionnaire is a compromise between length, content and the response rate expected. The response rate depends upon the motivation of the respondent to complete the questionnaire. This can be increased by an attractive layout and the use of closed questions that offer a range of possible answer options. The rating system for the answer options was kept from 1 to 7 as strongly agree to strongly disagree respectively. In some cases it varies from section to section and from question to question. The analysis of the returned questionnaire was carried out with the help of the spreadsheet package "Excel”.

The questionnaire was designed in five different sections. Section one deals with the overall background of the company. Section two is concerned with the top management support, skills available, knowledge and training of the employees regarding the successful implementation of CIM in SMEs. Section three of the questionnaire deals with regarding the marketing objectives of the company. Section four of the questionnaire deals with the company's support systems/techniques that are used for the successful implementation of CIM in SMEs. The section five of the questionnaire is concerned with the performance measures in the justification and implementation of CIM in SMEs. The response received by the companies including their age, turnover number of employees and amount spent on R\&D is shown in Table 1. 
Table 1: Background of the companies

\begin{tabular}{|c|c|c|c|c|c|}
\hline No. of companies & \multicolumn{5}{|c|}{ Background of the companies } \\
\hline & Nature of business & $\begin{array}{c}\text { Age of the } \\
\text { companies } \\
\text { (years) }\end{array}$ & $\begin{array}{c}\text { Turnover } \\
\text { (Millions) }\end{array}$ & $\begin{array}{c}\text { Number of } \\
\text { Employees }\end{array}$ & $\begin{array}{c}\text { R\&D } \\
\%\end{array}$ \\
\hline 3 & Cement Manufacturer & $20-30$ & $10-20$ & $70-99$ & $0.5-1$ \\
\hline 2 & Cooking oil Manufacturer & $30-40$ & $20-30$ & $51-80$ & $1-2$ \\
\hline 2 & $\begin{array}{c}\text { Soap and Detergent } \\
\text { manufacturer }\end{array}$ & 20 & 15 & $10-70$ & 0.5 \\
\hline 1 & $\begin{array}{c}\text { Shaving Razor products } \\
\text { Manufacture }\end{array}$ & 25 & 1.5 & $10-60$ & 2 \\
\hline 1 & Plastic component Manufacture & $10-15$ & $1-15$ & $10-40$ & $1-2$ \\
\hline 1 & Food Products Manufacturers & 6 & 6.7 & $51-99$ & 2 \\
\hline 2 & Chemical Manufacture & 10 & 20 & $10-90$ & $1-2$ \\
\hline 2 & Handicrafts Manufacture & 10 & 05 & $10-50$ & $0.5-1$ \\
\hline 2 & Textiles Industries & $10-20$ & $20-25$ & $60-85$ & $0.5-2$ \\
\hline 1 & Bakery Products Manufacture & $10-15$ & $5-10$ & $01-30$ & $1-2$ \\
\hline
\end{tabular}

Mailing of the questionnaire was chosen as the appropriate method for this project. The drawback of the questionnaire is the relatively low response rate which can be expected. However, the major advantages are the low cost and that less time is spent compared to interviews on the site. A further advantage is the possibility of choosing a larger and hence more representative sample size of companies. In order to ensure a high representative number of responses, a total of 100 manufacturing companies with workforce not exceeding to 99 were selected. The possibility of identifying and contacting a suitable employee to complete the questionnaire was considered. However, this was not practicable. Therefore, the addressee was chosen as the managing director/manufacturing director/production manager as these functions were thought to have the necessary overview of manufacturing systems design.

A total of 20 responses were received. $\mathbf{2 0}$ companies were of the opinion that, their company policy does not allow them to fill up the questionnaire. 15 companies have mentioned that, they have not yet implemented CIM in their companies. 20 companies have responded and duly filled in and returned the questionnaire. 25 questionnaires could not be delivered, and rest of the companies did not respond.

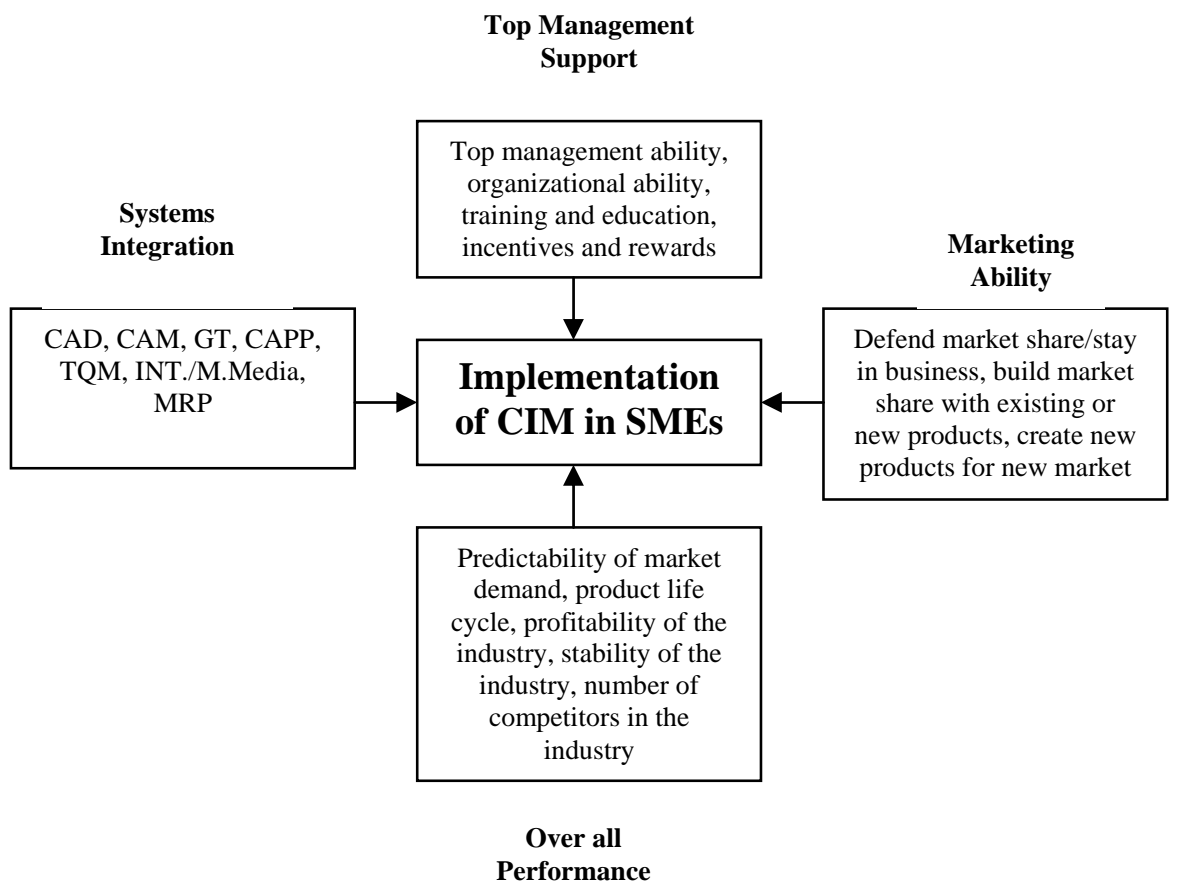

Figure 1: Framework/model for the implementation of CIM in SMEs 
A framework/model for the implementation of CIM systems/technologies in SMEs is shown in Figure 1. The issues of implementation of CIM in SMEs are discussed with respect to four dimensions that include top management support, marketing ability, systems integration and performance measurement in the justification and implementation of CIM in SMEs. Initially, quantitative research methodology was adopted to get data through empirical study which is presented in the next section.

\section{EMPIRICAL DATA ANALYSIS}

An empirical study of SMEs located in the province of Sindh in Pakistan was conducted using questionnaires. The background of the companies who have responded, has already been illustrated in Table 1 of section 4. A model/framework has been developed and presented in Figure 1 of section 4 as a base for empirical research to study the performance measurement while implementation of CIM in SMEs. The details follow hereunder.

\subsection{Top Management Support}

The full understanding, support and leadership of an organization's top management emerge as a crucial factor in almost all the studies for the successful implementation of CIM systems/technologies in SMEs. The importance of top management support goes far beyond the allocation of resources. It sets the priorities for the whole organization. Top management should focus on long-term strategic decisions based on quality, flexibility and responsiveness (Marri et al 2004).

During the empirical study SMEs were asked about the top management support for implementing the CIM system and was ranked from 1-7 as strongly agree to strongly disagree respectively in their companies. It was found that $\mathbf{4 0} \%$ of the companies responded that there is training and education facility available in their organization and also culture inside the company is favourable for implementing the same as it is ranked at 7. The same companies were of the opinion that there is lack of in house technological expertise, top management support and technological know how as is rated at 3 as shown in the Figure 2. $\mathbf{3 0 \%}$ of the companies were undecided about the lack of training and regarding the top management commitment and ranked as 4 while implementing the CIM system in their SMEs. So the data shows there is a favourable culture in their companies as scaled 6 . These companies expressed their favourable comments about the plants capability and its operational and cultural environment as ranked as $2 . \mathbf{2 0} \%$ of the companies were agree that there is lack of technological know how and lack in training and education while applying the CIM system as ranked 2. About the company culture, the organizations were undecided as scaled 4 . The same no of companies are little bit agree about lack of in house technologies as scaled as 3, but are confident about top management commitment as ranked as 6 . These companies have also admitted about the lack of technical know how and ranked as 2. Regarding the existing operational \& cultural environment as well as plant's capability they were some what agree and ranked as $3 . \mathbf{1 0 \%}$ of the companies were little bit disagree about the lack of training while applying CIM system, these companies also admit that the company's culture is unfavourable to the new technology and ranked 2. According to these organizations they were undecided about the lack of in house technological expertise as scaled 4. Companies also agreed about the lack of top management's support as ranked 2. as well as lack of technical know-how as ranked 3. The existing operational \& cultural environment is favourable where as they are undecided about the plants capability of the organization as ranked 4. 
TOP MANAGEMENT SUPPORT

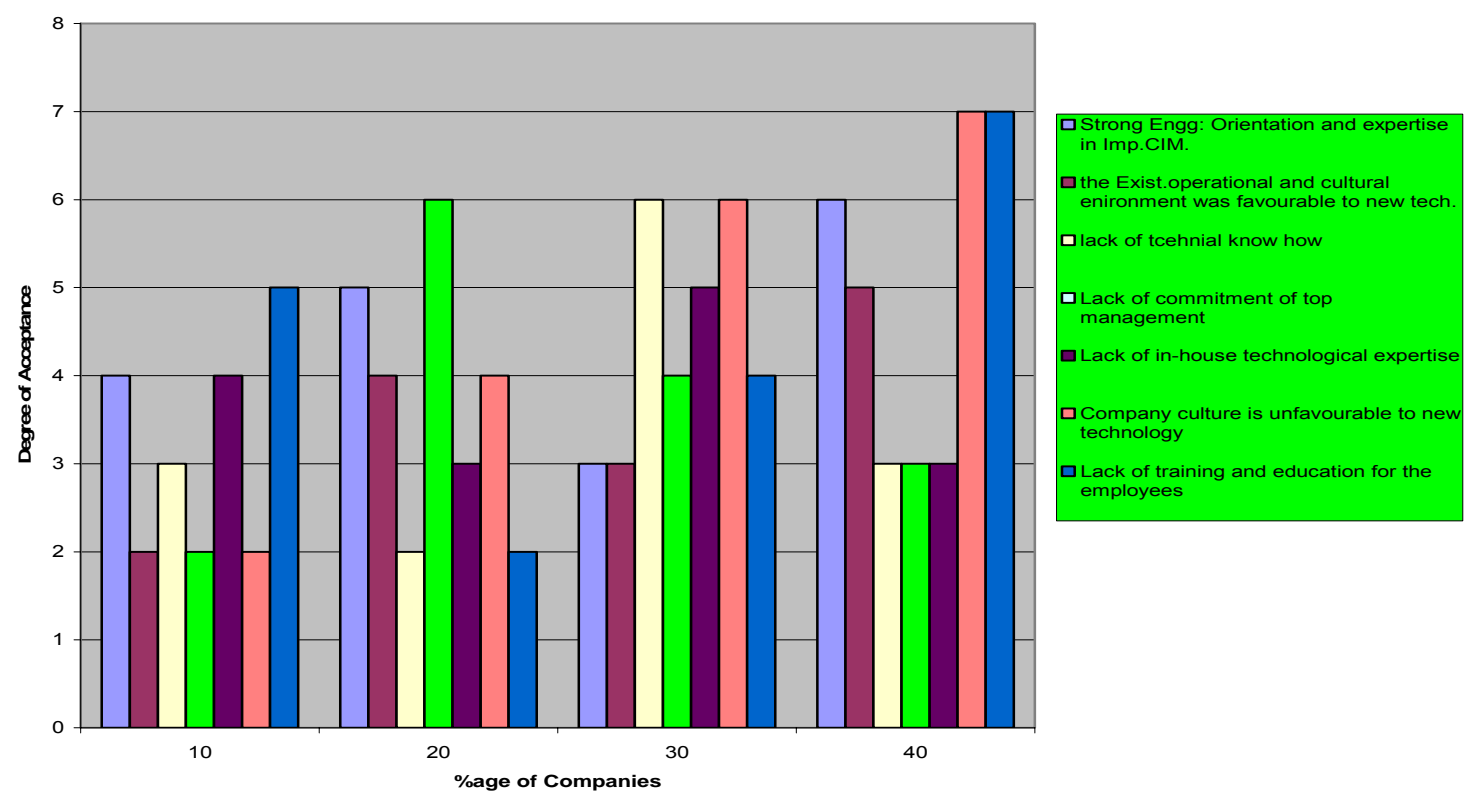

Figure 2: Top management support provided by the companies

Regarding the incentives and rewards offered by the companies, about $\mathbf{4 0 \%}$ of the companies were of the opinion that they provide all the basic facilities and incentives required by the employees during performing their work inside and outside the company which is ranked by 6-7 respectively. $\mathbf{3 0 \%}$ of the companies provide their workers with all the required facilities and incentives in terms of bonuses, training and education as well as medical care inside and out side of the organization as ranked 5. During the sick period the employees also benefited with sick pay while achieving the goals of the company they were provided with incentives and rewards as ranked 4 . The maintenance of the insurance was also an activity of the company as ranked by 6. it was very important for the organization to provide them employment empowerment, pension, vacation as ranked 3 . Only $\mathbf{2 0 \%}$ of the companies are lacking offering the medical care and sick pay as shown in Figure $3 . \mathbf{1 0 \%}$ of the companies consider important to provide their workers bonuses, training and education, and the pension as ranked 3. Other companies give less important to sick pay, incentives and rewards and medical care for the workers as ranked 2. Companies taking care of their workers usually provide them employment power, vacations and insurance to motivate them to achieve the aims and objectives of the company which is ranked at 4, 5 and 6 respectively. The incentives and rewards play a pivotal role in the nature and level of labour loading, union relations, productivity, training and motivation. Management therefore, should consider an incentive scheme as strategically important for the smooth running of their business and the proliferation of competition amongst staff.

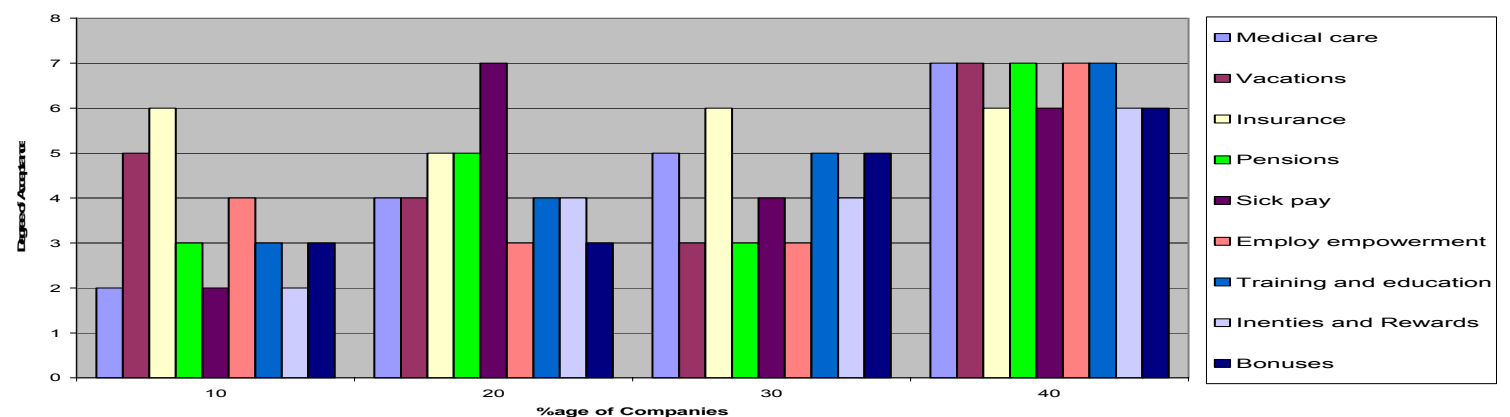

Figure 3: Incentives and rewards provided by the companies.

Shaikh et al.,

An Investigation into the Effects of Computer Integrated Manufacturing Systems in the Productivity of SMEs in Pakistan 
It is important that top management should improve the company's performance and technological strategy before implement CIM. Also, training is essential for the employees in the specific areas of the new system before its implementation. The main reason for the failure of CIM in SMEs is due to the lack of in-house technological expertise and its long-term vision to accept new technologies. Therefore, to overcome these deficiencies it is necessary to provide in-house and external sources of technological knowledge and training facilities to their staff in the company. Also top management's long-term vision and commitment plays an important role while implementing CIM in SMEs. The employees are the backbone of the company. To motivate them, it is necessary to provide them suitable incentives and rewards. The incentive and rewards concerns the change in the nature and level of labour loading, union relations, labour productivity, training requirements, and motivation. Increase in labour productivity improves the overall revenue of the organization and this opens up better and more opportunities in terms of higher education and salary for the employees, which in turn improve the overall motivation of the workers.

\subsection{System Integration.}

The system integration means linking together of previously separated activities within a single piece of technology or system. The issues regarding system integration for the implementation of CIM in SMEs includes: team working, alignment between business strategy and manufacturing strategy, internet, multimedia, Advance guided vehicles (AGVs), robots, , (computer aided design,) computer aided manufacturing (CAM), CAPP, GT, JIT, concurrent engineering (CE) TQM, FMS, and business process re-engineering (BPR).

(Marri H.B et al).

An empirical Data shows that 07, companies were using the CAD ,CAM, GT, TQM and Internet / Multimedia systems in their organizations in order to meet their goals. 05 companies adopted GT, TQM and Internet / Multimedia systems. 04 organizations were in favour of adoption for CAPP, TQM and Internet /Multimedia to improve their productive aspects of out put. Same time an other 04 organization were using TQM, Internet / Multimedia an MRP systems as shown in Table 2.

Table 2: CIM systems used by the companies.

\begin{tabular}{|c|c|c|c|c|c|c|c|}
\hline $\begin{array}{c}\text { No. of } \\
\text { companies }\end{array}$ & CAD & CAM & CAPP & GT & TQM & INT/ M. MEDIA & MRP \\
\hline & & & & & & & \\
\hline 07 & $\sqrt{ }$ & $\sqrt{ }$ & & $\sqrt{ }$ & $\sqrt{ }$ & & $\sqrt{ }$ \\
\hline 05 & & & & $\sqrt{ }$ & $\sqrt{ }$ & $\sqrt{ }$ & \\
\hline 04 & & & $\sqrt{ }$ & & $\sqrt{ }$ & $\sqrt{ }$ & \\
\hline 04 & & & & & $\sqrt{ }$ & $\sqrt{ }$ & $\sqrt{ }$ \\
\hline
\end{tabular}

Regarding the reasons for introducing CIM systems/technologies in SMEs, during an empirical study, it was asked about the reasons for implementing CIM systems/technologies in their companies. Reasons were also mentioned during the study such as: to improve efficiency, to reduce cost, to improve quality, to reduce time to market, automation, to reduce work in progress and for better working environment. The responses received by the companies are mentioned in Table 3.

During collecting the data, $40 \%$ of the companies have indicated that, the reasons for implementing CIM systems/technologies were to improve efficiency and to reduce cost to compete in the global market. 30\% of the companies have mentioned to reduce cost of their product was the reason for implementing CIM systems/technologies. $20 \%$ of the companies have mentioned to improve efficiency, improve quality of the products and reduce time to market were the main factors. Only 10 $\%$ of the companies have indicated that, while using this system, the benefit they draw as to reduce

Shaikh et al.,

An Investigation into the Effects of Computer Integrated Manufacturing Systems in the Productivity of SMEs in Pakistan 
time to market, to improve efficiency and the better working environment, was the reason for introducing CIM as shown in table 3.

Table 3: Reasons for introducing CIM systems/technologies in SMEs

\begin{tabular}{|c|c|c|c|c|c|c|c|}
\hline $\begin{array}{c}\text { \% of } \\
\text { Companies }\end{array}$ & $\begin{array}{c}\text { To improve } \\
\text { efficiency }\end{array}$ & $\begin{array}{c}\text { To reduce } \\
\text { cost }\end{array}$ & $\begin{array}{c}\text { To improve } \\
\text { quality }\end{array}$ & $\begin{array}{c}\text { To reduce } \\
\text { time to } \\
\text { market }\end{array}$ & Automation & $\begin{array}{c}\text { To } \\
\text { reduce } \\
\text { WIP }\end{array}$ & $\begin{array}{c}\text { For better } \\
\text { working } \\
\text { environment }\end{array}$ \\
\hline 40 & $\sqrt{ }$ & $\sqrt{ }$ & & & & & \\
\hline 30 & & $\sqrt{ }$ & & & & & \\
\hline 20 & $\sqrt{ }$ & & $\sqrt{ }$ & $\sqrt{ }$ & & & \\
\hline 10 & $\sqrt{ }$ & & & $\sqrt{ }$ & & & $\sqrt{ }$ \\
\hline
\end{tabular}

The flexibility measures the versatility of the processes of the enterprises and has the ability of resources to cope with changes in product design, product mix, batch size, operating sequence and production levels (Gunasekaran and Thevarajah, 1999). The conducted data shows $40 \%$ of the companies were agree to get the good degree of flexibility by using the CIM system and $20 \%$ of companies consider it high degree of flexibility. $30 \%$ and $10 \%$ of companies scaled it average and below average degree of flexibility respectively as shown in table 4.

Table 4: CIM systems coped with equipment/product flexibility.

\begin{tabular}{|c|c|c|c|c|c|}
\hline $\begin{array}{c}\text { o/o of } \\
\text { companies }\end{array}$ & $\begin{array}{c}\text { High degree } \\
\text { of flexibility }\end{array}$ & $\begin{array}{c}\text { Good degree of } \\
\text { flexibility }\end{array}$ & $\begin{array}{c}\text { Average degree of } \\
\text { flexibility }\end{array}$ & $\begin{array}{c}\text { Below average degree of } \\
\text { flexibility }\end{array}$ & $\begin{array}{c}\text { It has not } \\
\text { coped at all }\end{array}$ \\
\hline 40 & & $\sqrt{ }$ & & & \\
\hline 30 & & & $\sqrt{ }$ & & \\
\hline 20 & $\sqrt{ }$ & & & & \\
\hline 10 & & & & $\sqrt{ }$ & \\
\hline
\end{tabular}

It is observed from the empirical data analysis that most of the organizations have concentrated on the TQM, other CIM enablers were less focused in their companies. Hence these enterprises can offer other CIM systems such as CAPP, CE, EDI and AGVs to maximize their production and minimize work in progress. Overall, most of the survey companies have achieved a good degree of flexibility in their organizations after implementing CIM systems. The future research area of CIM is to develop a system like computer aided tools (artificial intelligence, expert systems) for evaluating different alternative processes of developing CIM by offering various methods.

\subsection{Marketing objectives}

In the business Philosophy, the term marketing has been narrated in different perspectives. In general marketing places the consumer at the centre of the firm's activities. It is an integrated process whereby a firm aims not only to satisfy its customers more effectively and efficiently than its competitors do but also to establish long-term profitability. However, there is some evidence that in many organizations marketing has not been fully adopted as a philosophy and strategy and that marketing planning is neither understood nor implemented (Morris and Morris, 1992). Marketing approach is applied to each industry through specific practices developed to suit the needs of the trade. Since founders usually start a business in a sector in which they have personal experience, it might be expected that they would have the expertise to adopt industry-specific features of marketing. However, many owner-managers who have a technical or production background and know the business from within do not have the broader perspective provided by marketing (Ahopelto and Raatikarin, 1994). In the empirical study, the SMEs were asked to indicate their achievements regarding the marketing objectives of the companies after the implementation of CIM systems as ranked from 1 to 7 as not important to very important respectively. $40 \%$ of the companies have rated defend market share/stay in business and to create new market for new products at the scale of 7 shows a great improvement in their marketing. The same companies have achieved good improvements in building market share with

Shaikh et al.,

An Investigation into the Effects of Computer Integrated Manufacturing Systems in the Productivity of SMEs in Pakistan 
existing or new products as it is rated at -6 as shown in Figure $4.30 \%$ of the companies have achieved very good improvements in all the three areas as ranked at $6.20 \%$ of the companies have received improvements to a certain extent in two areas as they are rated at $5.10 \%$ of the companies have mentioned that, they have reached to very little improvements in defending and creating new market for new products.

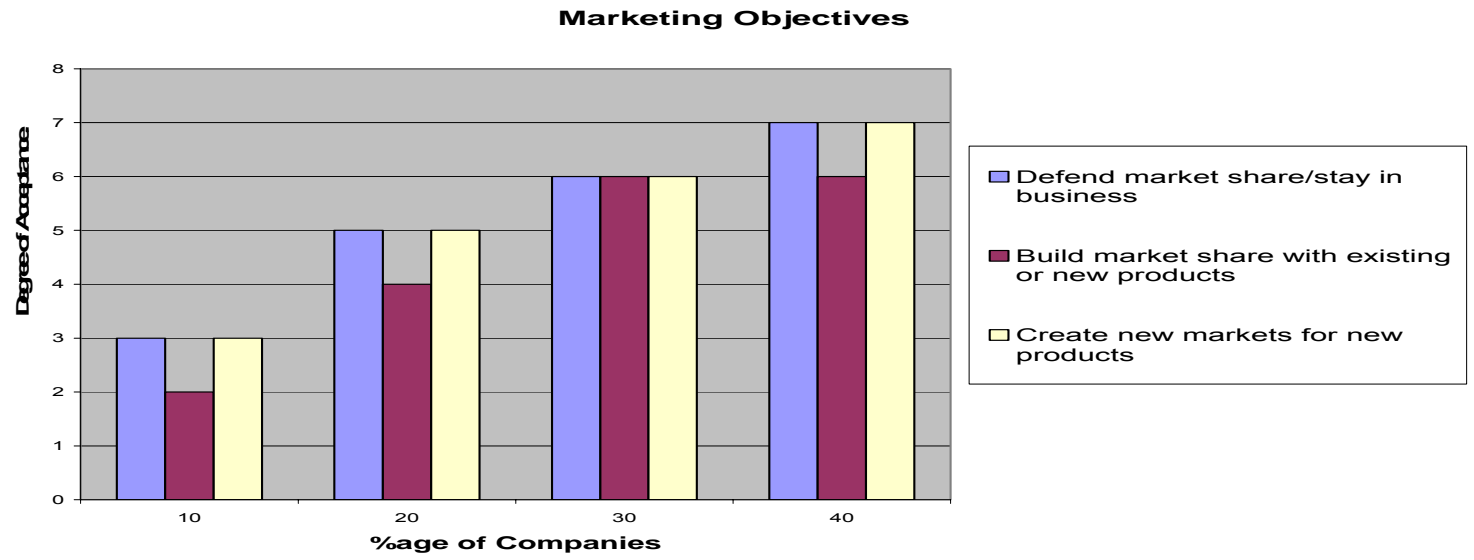

Figure 4: Marketing objectives of the companies.

Marketing is responsible for keeping an eye and ear on the market place in order to identify new opportunities and possible products or services that might be appropriate. Interestingly, limited financial resources did create problems in conducting quality marketing, expanding new markets, extending credit, and dealing with advertizing costs The adoption of CIM gives SMEs a greater number of growth options to enter new markets and to create new products than SMEs relying on traditional manufacturing technologies. A further benefit is that, as a result, product designs are likely to be more frequent and SMEs with CIM have the opportunity to respond more quickly to market conditions and to improve market share.

\subsection{The Over all Performance.}

The technological performance of small and medium enterprises is emphasized to focus on what enterprises actually do technologically. An enterprise must bring together at each productive point people with the right technological knowledge, equipment with the right technological capabilities, and materials suitable for the purposes and the techniques to be applied. If anywhere in the process failures occur, they will be measured in loss of relevance of industry to the needs of the country, loss of productivity, loss of quality in the products produced, or some external cost such as pollution of the environment. Difficult as achieving this level of performance may be, the task facing the enterprise is still greater. Technology performance is not just performance at the moment; it must be sustained, and the sustenance is through creative destruction. Thus the people, equipment, facilities, and processes in the enterprise must embody sufficient technological knowledge and flexibility to select wisely among alternative techniques available for each step in the process, to adapt technology to meet local circumstances and changes in local circumstances, and ideally to develop new technology when appropriate and necessary (Rothwell and Dodgson, 1992).

According to the empirical study conducted, $40 \%$ of the companies have mentioned that, their marketing is growing with profitability and stability after the implementation of CIM. On the other hand they are less predictable in market and competitors. 30\% of the companies have mentioned that, they have achieved a good progress in almost all the areas of market target as mix response as mentioned above. $20 \%$ of the companies have indicated that, they have also achieved an average achievement in all the areas of the market target of the companies with medium Predictability of 
market and marketing as shown in Figure 5. 10\% of the companies have also gained a little bit progress in all parameters.

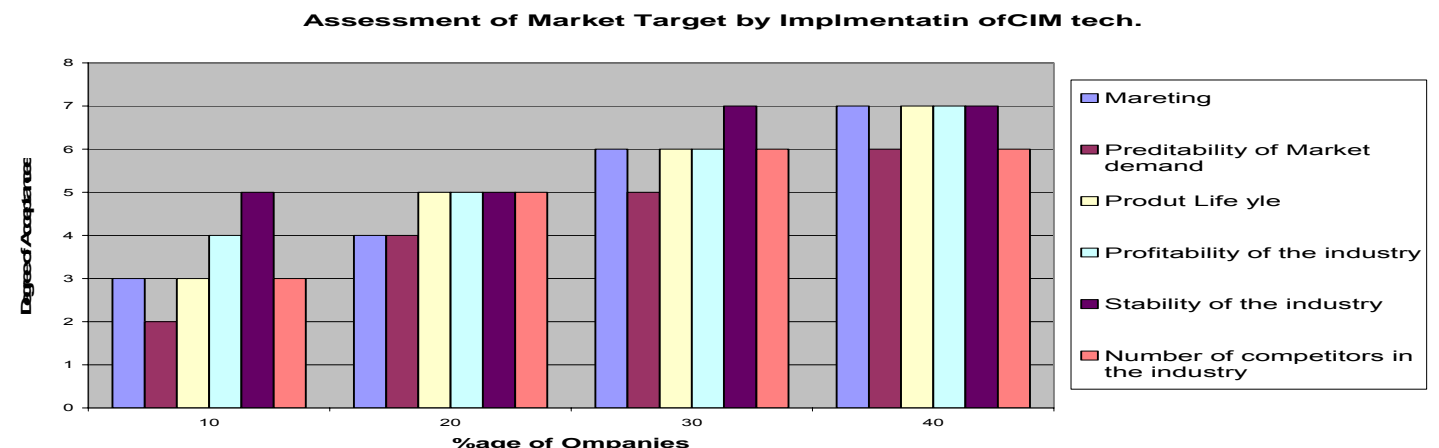

Figure 5: performance measurements of the companies.

The overall performance focuses to provide quality goods or services will influence its reputation in the market. That reputation or image, will in turn affect customer loyalty, and will influence future demand. A high reputation will facilitate and complement other marketing/promotional activities, and make them more cost effective. SMEs can achieve good degree of their performance by implementing CIM. Those SMEs who have implemented CIM have gained a lot in the business and have defended in their market share.

\section{CONCLUSIONS AND SUGGESTIONS}

The purpose of this research was to identify the main constraints of Pakistani SMEs that intercepts their growth, ultimately depriving their potential market share. Our research indicates that the government of Pakistan should provide all the essential benefits and facilities in all areas like, technological aspects, manpower, infrastructure, tax rebate, finance, for creating favourable environment so that the SMEs could get the rid of multidimensional pressures, hence the organizations should immediately adopt the computer integrated manufacturing systems with its all parameters to enhance their productivity in the broad sense.

The human factors are important in the areas such as installation, operation and maintenance, and safety. The empirical study results shows that, SMEs are not considering human factors in an advance while implementing CIM. To make CIM implementation successful, it is necessary for top management to consider human factors at the earliest stage of the planning and implementation of CIM in SMEs. If not, a CIM project may fail as workers struggle to operate and maintain a system superficially design to prevent their efforts. There is a need to establish the level of skill and training required in order to implement CIM in SMEs.

The support of appropriate resources and assistance in implementing CIM in SMEs is a further responsibility of top management. They must support all efforts for CIM implementation by providing financial support as well as time needed for the teams to pursue their project and to implement it. Communication with customers is a fundamental and extremely important action for senior managers to undertake, in order to promote and participate in a successful CIM implementation process.

\section{Acknowledgement}

The authors are extremely thankful to the Higher Education Commission of Pakistan for providing financial assistance to carry out this research project. The thanks also go to the companies for providing useful data regarding this paper to make a little contribution in the passage of research. The authors are also grateful to the Department of Industrial Engineering and Management, Mehran 
University of Engineering and Technology, Jamshoro, Sindh, Pakistan and the Department of Information Systems and Computing, Brunel University West London for providing essential assistance to make this work possible.

\section{REFERENCES}

Ahopelto, J., and Raatikainen, I., 1994. 'Network commitment as a competition parameter of marketing viewpoint in advertizing'. Kuopio University Publications, Finland, pp. 167-191.

Al-Ahmari, A.M.A., 2002. 'Implementing CIM system in SMEs'. International journal of Computer applications in technology, 15 (1/2/3): 122-127.

Browne, J., Harhen, J., and Shivnan, J., 1988. 'Production management systems: A C I CIM perspective'. Addison Wesley, Reading, MA.

Bryman, A., 1988. 'Quantity and quality in social research'. Published by Routledge, London and New York.

Dangayach , G.S., and Deshmukh, S.G., 2005. Journal of Manufacturing Technology Management, 16 ( 5): 483-496.

Groover, M.P, 1999. 'Automation production system and computer integrated manufacturing'. Prentice Hall, New Jersey.

Gunasekaran, A., and Thevarajah, K., 1999. 'Implications of computer-integrated manufacturing in small and medium enterprises: an empirical investigation'. International Journal of Advanced Manufacturing Technology, 15 (4): 251-260.

Gunasekaran, A., and Marri, H.B., 2002. 'Implementation of computer integrated manufacturing a survey of integration and adaptability issues'. International Journal of Computer Integrated Manufacturing, 10 (1-4): 266-280.

Gunasekaran, A., Marri, H.B, and lee, B., 2000. 'Design and implementation of computer integrated manufacturing, in small and medium-sized enterprises: A case study’. International Journal of Advanced Manufacturing Technology, 16 (1): 46-54.

Gunn, T.G., 1987. 'Manufacturing for competitive advantages - becoming a world class manufacture'. Ballinger Publishing Company, USA.

Harrington, J., 1978. Computer integrated manufacturing’. Krieger Publishing Company, New York, USA.

Johansen, J. Karmarkar, U.S, Nanda, D, and Seidmann, A., 2001. 'Business experience with computer integrated manufacturing, a survey of current strategy and practice'. Proceedings of the 28th annual Hawaii International Conference on system Sciences, 970-979.

Lefebvre, L.A., Lefebvre, E., and Harvey, J., 1996. Intangible assets as determinants of advanced manufacturing technology adoption in SME's: toward an evolutionary model, International journal of IEEE Transactions on Engineering Management, 43 (3): 307-322.

Marri, H.B., and Sohag, R.A., 2004. 'Top management role for facility location and layout when implementing advanced manufacturing technology'. 2nd International Industrial Engineering Conference, K.S.U, Riyadh, Saudi Arabia.

Marri, H.B., Gunasekaran, A., and Grieve, R.J., 1998. 'An investigation into the implementation of computer integrated manufacturing in small and medium enterprises'. International Journal of Advanced Manufacturing Technology, 14 (12): 935-942.

Morris, L.J., and Morris, J.S., 1992, The changing manufacturing environment: implications for marketing, The Journal of Business and Industrial Marketing, 7 (2): 21-30.

SMEDA Pakistan web page, www.smeda.org.gov.pk

Rothwell, R., and Dodgson, M., 1992. 'European technology policy evolution: convergence towards SMEs and regional technology transfer'. International Journal of Technovation, 12 (4): 223-238. 